\title{
Micro-Hole Multi-Point Punching System Using Punch and Die Made by EDM*
}

\author{
Mark BROOMFIELD**, Toshihiko MORI**, Teruaki MIKURIYA*** \\ and Kazushi TACHIBANA*** \\ **Department of Complex System Science, \\ Graduate School of Information Science, Nagoya University, \\ Furu-cho, Chikusa-ku, Nagoya 464-8603, Japan \\ E-mail:mabroomfield@yahoo.com \\ ${ }^{* * *}$ Department of Mechanical Engineering, \\ Graduate School of Engineering, Nagoya University, \\ Furu-cho, Chikusa-ku, Nagoya 464-8603, Japan
}

\begin{abstract}
In this research a multi-point micro punch and die system was developed. The process of electric discharge machining (EDM) was used to produce both the punch and die. The punches were machined from a $5 \mathrm{~mm}$ diameter tungsten and a $10 \mathrm{~mm}$ diameter tool steel round rods by wire electric discharge machining (WEDM), using a $200 \mu \mathrm{m}$ diameter wire electrode. The die holes were made using the punch as the electrode. The EDM process of the holes was carried out on a newly developed desktop EDM machine. The punch and die placed on a micro-die set and then on a micro press were used to produce micro-holes using an automatic control system developed for this process. Experiments to produce $50 \mu \mathrm{m}$ to $67 \mu \mathrm{m}$ square micro-holes on $50 \mu \mathrm{m}$ thick aluminum, $30 \mu \mathrm{m}$ thick copper and $20 \mu \mathrm{m}$ thick stainless steel foils were conducted. The capabilities of multi-point punching using the tungsten punch and a tool steel punch were examined and tungsten was chosen as the material of choice for making the punch tool. A scanning electron microscope confirmed that the holes produced are clean, and the sheared surfaces smooth. The punch tool showed no signs of deformation or cracks even after repeated punching.
\end{abstract}

Key words: Multi-Point Punch, Gold Plating, Micro-Die Set, EDM, Clearance

\section{Introduction}

Micromachining technologies have remained one of the most interesting fields of modern research and development in both industry and academia. The ongoing development in micro and high density products has led to continued research and development in the field of micro-hole technology. Coupled with this is a need for greater precision and accuracy in a number of technologies and researches all seeking to provide smaller holes in the micrometer order. The more popular fields include EDM machining, vibration EDM machining, micro-punching using $\mathrm{SiC}$ fiber, laser micro-hole machining and other various processes ${ }^{(2)-(4)(1)}$. EDM and laser processes, which are currently the leading manufacturing methods of producing micro-holes and slots, are limited because of production cost, lengthy processing time, and limitations in the materials that can be used in these processes. In addition, these methods have faced some amount of difficulties in applying them across various industries because they are not suited for mass production ${ }^{(2)}$. On the other hand, punching which is a deformation process has remained the most 
preferred method of mass production ${ }^{(5)}{ }^{(6)}$. Table 1 shows some of the popular micro machining processes with some of the main advantages and disadvantages of the respective processes highlighted.

Table 1. Micro Machining Process Evaluation

\begin{tabular}{|c|c|c|c|c|}
\hline Process & Principle & $\begin{array}{c}\text { Minimum } \\
\text { feature size }\end{array}$ & Advantages & disadvantages \\
\hline $\begin{array}{c}\mu \text {-Molding \& } \\
\text { Casting }\end{array}$ & Solidification & $500 \mu \mathrm{m}$ & Mass production & Spring-Back \\
\hline$\mu$-Punching & $\begin{array}{c}\text { Plastic } \\
\text { Deformation }\end{array}$ & $50 \mu \mathrm{m}$ & Mass production & $\begin{array}{c}\text { Need uniform } \\
\text { clearance }\end{array}$ \\
\hline $\begin{array}{c}\mu \text {-Milling \& } \\
\text { Grinding }\end{array}$ & Cutting & $25 \mu \mathrm{m}$ & $\begin{array}{l}\text { Good geometric } \\
\text { accuracy. Good } \\
\text { surface finish }\end{array}$ & $\begin{array}{c}\text { Tool deflection/ } \\
\text { damage due to } \\
\text { cutting force }\end{array}$ \\
\hline $\begin{array}{c}\text { Stereo- } \\
\text { Lithography }\end{array}$ & Lamination & $12 \mu \mathrm{m}$ & $\begin{array}{c}\text { Complex 3D } \\
\text { shapes }\end{array}$ & $\begin{array}{c}\text { Limited work } \\
\text { materials } \\
\end{array}$ \\
\hline Eximer laser & Ablation & $10 \mu \mathrm{m}$ & $\begin{array}{c}\text { No heat damage } \\
\text { on surfaces }\end{array}$ & $\begin{array}{c}\text { Limited work } \\
\text { materials }\end{array}$ \\
\hline $\begin{array}{c}\mu \text {-EDM \& } \\
\text { Laser }\end{array}$ & $\begin{array}{c}\text { Melting- } \\
\text { Vaporization }\end{array}$ & $5 \mu \mathrm{m}$ & Negligible force & $\begin{array}{c}\text { Possible surface } \\
\text { damage and } \\
\text { low MRR }\end{array}$ \\
\hline FIB & Sputtering & $0.2 \mu \mathrm{m}$ & Stress free & Low MRR \\
\hline
\end{tabular}

Although Chern and Wang ${ }^{(4)}$ have developed a micro-forming and micro-punching machine, alignment devices to ensure precise centering are needed because both punch and die are made separately. This can result in increases in production time and processing cost, and the possibility of miss alignment remains a cause for concern. In this research the development of a multi-point punch and die set is examined. Tungsten and tool steel are used as the material for making the punch and steel (S45C in JIS) for making the die.

Table 2. Properties of tungsten

\begin{tabular}{|c|c|}
\hline Property & Value \\
\hline Atomic weight & $183.85 \mathrm{~g} / \mathrm{g}$ atom \\
\hline Density & $19.25 \mathrm{~g} / \mathrm{cm}^{3}$ \\
\hline Melting point & $3410^{\circ} \mathrm{C}$ \\
\hline Ultimate strength & $1510 \mathrm{MPa}$ \\
\hline Young's Modulus & $411 \mathrm{GPa}$ \\
\hline
\end{tabular}

Tungsten was chosen as the preferred material because of its availability, its properties and its ability to punch various materials successfully. Table 2 shows some the mechanical properties of tungsten. The multi-point punch is a development of the micro-punching system developed by Mori ${ }^{(2)}$, one of the authors of this paper, using SiC fiber as the material for the punching tool. Although some of the major difficulties were overcome, namely alignment between punch and die, continued research was necessary to make this system applicable to the industry. The decision to develop a multi-point punching system was based on the ever increasing demand in various manufacturing sectors, coupled with the success of developing a single point punch using similar methodologies, systems and processes in earlier experiments. Areas of demand include the miniaturization of electronic components for micro-systems technologies (MST) and micro-electromechanical systems 
(MEMS). Pins for IC-carriers, fasteners, micro-screws and contact springs are just some of the typical parts in demand. Other areas of application include medical components, sensor technology, telecommunication and high-tech security systems ${ }^{(4)(7)(8)}$.

This paper describes the different techniques and processes used to develop the multi-point punch and die. It explores the possibility of using other materials, other than tungsten, for making the punch tool, namely, tool steel (SK3). Based on the experiments, the limitations of the tool steel punch are out-lined and the reasons for selecting tungsten as the material of choice are stated. The importance of proper clearance between punch and die is discussed and the processing parameters that are essential to obtaining near optimum clearance for trial punching the test materials are presented. It concludes by presenting and discussing the results of the trial punching experiments.

\section{Experimental Method}

\subsection{Punch Making Process}

The multi-point micro-punch was made by wire EDM (WEDM) using the Mitsubishi DIAX FX10 EDM machine. Figure 1 shows the machining process of the punch. Before the punch points were machined one end of the $5 \mathrm{~mm}$ diameter round bar was machined into a square prism of height $2.5 \mathrm{~mm}$ and square edges of $1.5 \mathrm{~mm} \times 1.5 \mathrm{~mm}$, as shown in Fig. 1(a). This was done by wire EDM. Next, using a wire electrode of diameter $200 \mu \mathrm{m}$ the four point punch was machined in two stages as shown in Fig. 1. In Fig. 1(c), the center gutter was machined by the wire electrode which had a discharge gap of $20 \mu \mathrm{m}$. The wire electrode was then off-centered a distance of $600 \mu \mathrm{m}$ from the center and machined as shown in Fig. 1(d). The bar was then rotated $90^{\circ}$ and the processes of (c) and (d) were repeated. That is the rough machining stage. After the rough machining stage, the bar was returned to its original position and machining was done on the inner portions of the punch walls as shown. In Fig. 1(f) finish machining of the outer sections of the punch points was done by off-centering the electrode wire by a distance of $370 \mu \mathrm{m}$. The bar was then rotated by $90^{\circ}$ and the processes of (e) and (f) were repeated. The direction of machining is indicated by the arrows affixed to each drawing. Careful machining was done to ensure that all four punch points are equal in length and size and that they are parallel to each other. This was of extreme importance because the punch was also used as the electrode for making the die holes. Any unevenness would increase the discharge processing time, and adversely affect the punching operation. This was one of the key processes that had to be controlled to ensure reduction in the die hole processing time and the amount of material removed from the punch tool surface ${ }^{(9)(10)}$.

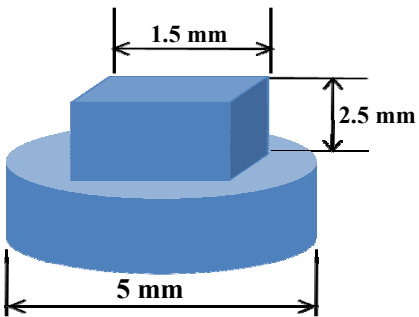

(a) Square prism

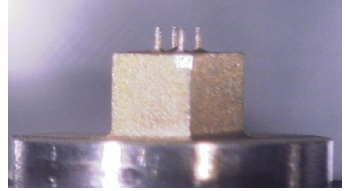

(b) Four point punch

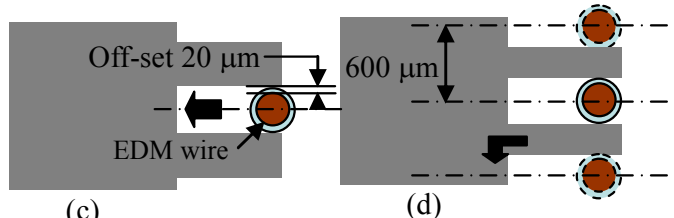

(c)

(d)

Rough machining of punch points

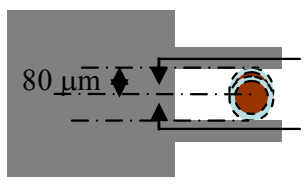

(e)

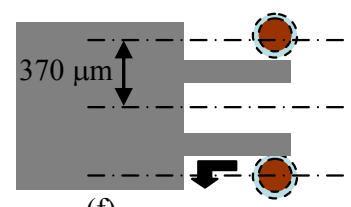

(f)
Finish machining of punch points.

Fig.1 Punch making process 
Figure 2 shows various views of the one of four point punches made in this research. Detailed dimensions of the punches used in this research are shown in figure 10.

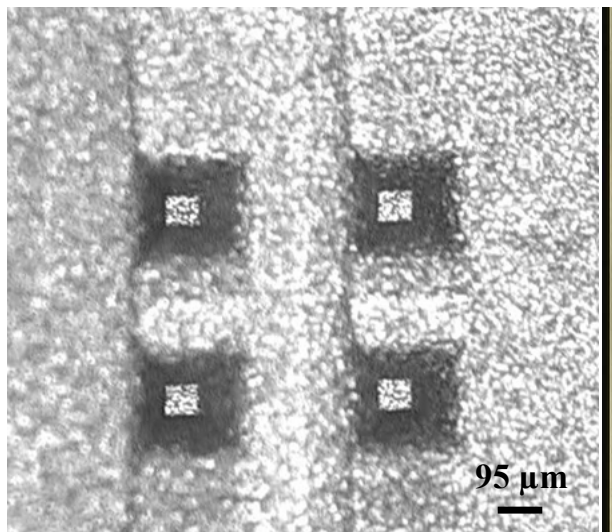

(a) Upper view

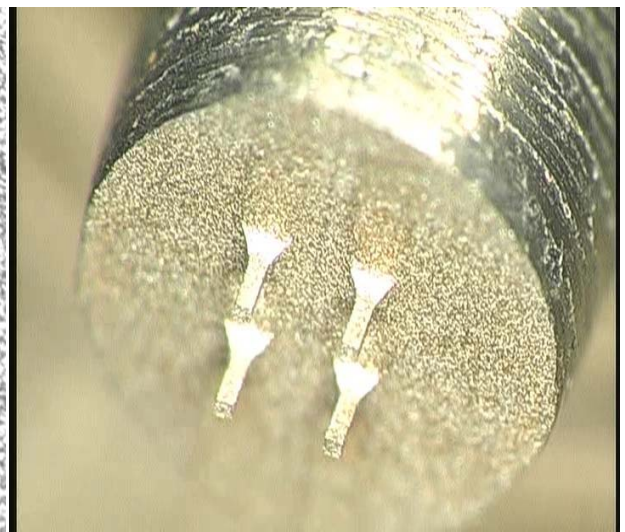

(b) Angular upper view

Fig.2 Various views of four point punch

\subsection{Die Making Process}

Figure 3 shows the die making process. First a gutter of about $1.5 \mathrm{~mm}$ depth and $2 \mathrm{~mm}$ width was cut in a plane machined from hard steel in the shape shown in (a). The tip of the gutter was machined by end mill to a width of $1 \mathrm{~mm}$ and the thickness of the area where the holes were to be machined was about $70 \mu \mathrm{m}$. The die surface was then polished to obtain a thickness of $20 \sim 30 \mu \mathrm{m}$ across the thinnest portion of the face where the hole was machined in (b), using \# 2000 emery paper and $0.05 \mu \mathrm{m}$ diamond powder. The die finished without making the holes was fastened to a micro die-set together with the prescribed micro punch as show in Fig.4. Next the micro die-set was set into a specially made desktop EDM machine as shown in Fig. 5. In this machine the process of Fig.3 (c) in which the die holes were made by electric discharge machining (EDM) using the four point micro punch as the electrode was carried out. The holes were machined on the thinnest part of the die and the other portion provided support for the holes. Table 3 shows the discharge conditions under which the die holes were machined. Figure 6 shows a picture of the section of the die surface where the holes were machined by the process of EDM. The dimensions of the holes are also shown.

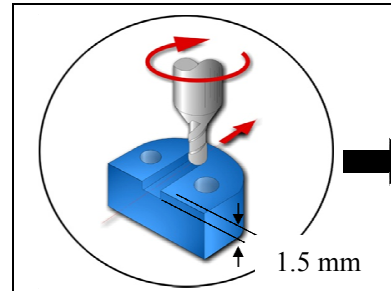

(a) Machining of gutter

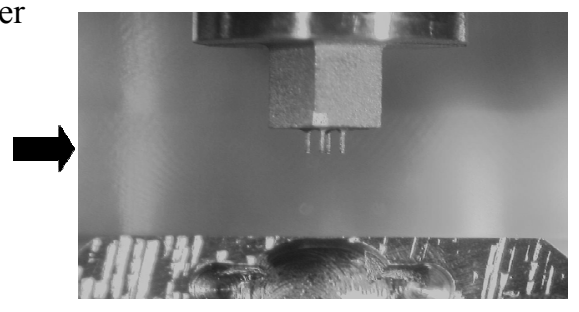

(c) EDM process using punch as electrode

Fig.3 Die making process

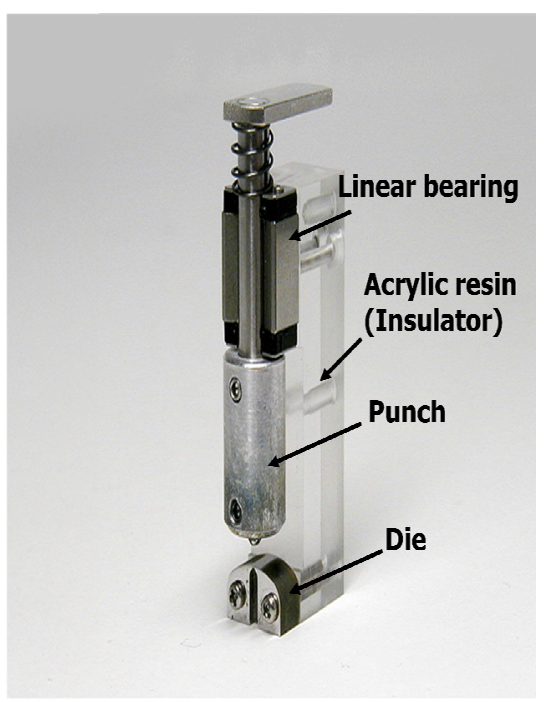

Fig.4 Micro die-set 


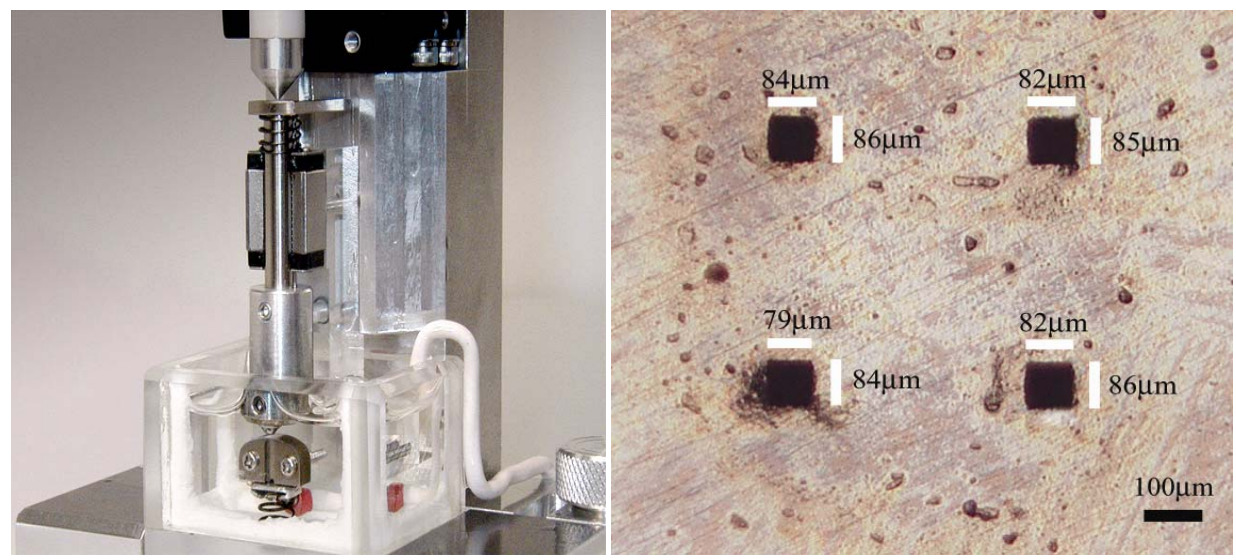

Fig.5 Desktop EDM

Fig.6 Die holes produced by EDM with punch

Table 3. Electric discharge conditions

\begin{tabular}{|c|c|}
\hline Parameter & Quantity \\
\hline Capacitance & $1000 \sim 2000 \mathrm{pF}$ \\
\hline Voltage & $40 \sim 45 \mathrm{~V}$ \\
\hline Resistance & $200 \mathrm{k} \Omega$ \\
\hline Current & $6.15 \mathrm{~A}$ \\
\hline $\begin{array}{c}\text { Electric discharge } \\
\text { time }\end{array}$ & $14 \sim 18 \mathrm{hr}$ \\
\hline Punch diameter & $50 \mu \mathrm{m}(\mathrm{SK} 3)-64 \mu \mathrm{m}(\mathrm{W})$ \\
\hline Clearance & $7.8 \mu \mathrm{m}$ \\
\hline
\end{tabular}

\subsection{Obtaining Appropriate Clearance}

In order to obtain appropriate clearance for the punching process the correct discharge condition for the EDM process of the die holes had to be predetermined. This was done through a series of punching clearance experiments and testing. First selected parameters of the discharge R-C circuit were varied individually while keeping the others constant. Parameters such as the capacitance, voltage, frequency and resistance were varied respectively with various electrode diameters. After a series of testing, except for a slight variation in the voltage as shown in table 3, the parameters for the resistance, frequency and voltage were determined and fixed. Next capacitance of $500 \mathrm{pF}, 1000 \mathrm{pF}, 2000 \mathrm{pF}, 3000 \mathrm{pF}$ $4000 \mathrm{pF}$ and $4700 \mathrm{pF}$ were used respectively with electrodes of the same diameter ranging from $50 \mu \mathrm{m}$ to $150 \mu \mathrm{m}$ for the die hole discharge process. The clearance in each case was calculated and trial punching was conducted to determine which clearance was best for effective punching. Based on the results the values of the capacitance as shown in table 3 were chosen. As the diameter of the punch tool used for the discharge process changed the value of the capacitance needed to obtain sufficient clearance was also changed.

\subsection{Flattening of Punch Points}

Flattening of the punch tool tip surface was done twice, before and after the EDM process of the die holes. Flattening before the EDM process was done to ensure that all four points of the punch were flat. This was because the points became slightly rounded after the punch was made. Flattening was done to ensure that the die holes were machined simultaneously. This reduced the discharge processing time and the electrode consumption 
rate of the punch ${ }^{(9)}$. The second flattening was necessary because after the die holes were machined the edges of the punch points appeared slightly round and uneven. However, for the tool to be an effective punching tool the surfaces of the punch must be flat and acute ${ }^{(10)}$. Flattening was done by reversing the polarity of the work and punch, and by placing a strip of $40 \mu \mathrm{m}$ thick copper and a strip of $20 \mu \mathrm{m}$ thick hard steel between the work and the punch. This increased the rate of material removal from the punch surface, while preventing material removal from the foil. Separation of punch and die after the die holes were machined was impossibly. However, the use of the die-set on which both the punch and die were fixed made this operation possible without affecting the alignment of the punch and die unit. Figure 7 shows the micro-punch tool tip surface after the EDM process of the die holes (a) and after the flattening process (b).

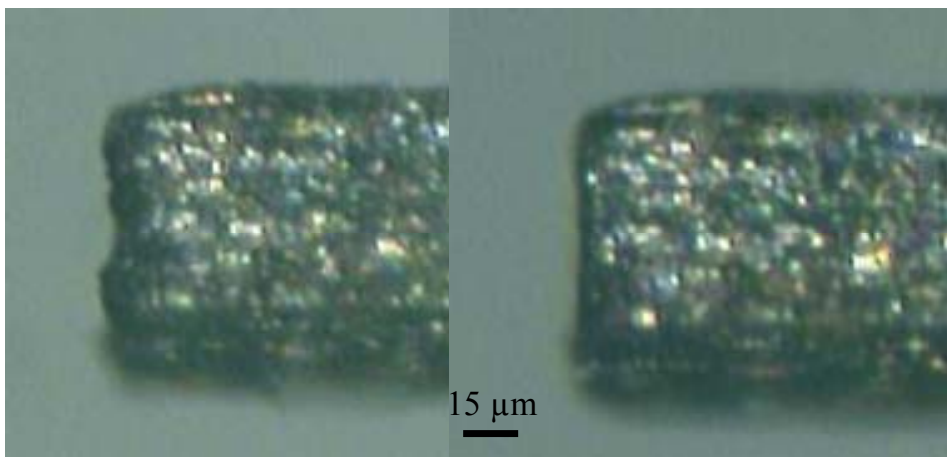

(a) After EDM

(b) After flattening

Fig.7 Micrographs of punch tip before and after flattening

\subsection{Control and Measurement}

The entire punching operation was controlled by a computer. The movement of the punch was controlled by the use of a piezoelectric actuator, connecting the micro punching system to the computer, and the movement of the material to be punched by stepping motor. The laminating piezoelectric actuator used provided a maximum displacement of $68 \mu \mathrm{m}$ and a generating force of $800 \mathrm{~N}$ was used for the primary drive. Figure 8 shows the linear relation between direct current voltage $(\mathrm{V})$ and displacement $(\mu \mathrm{m})$. The punching speed and movement were also controlled by the computer, which was connected to the piezo driver via $\mathrm{D} / \mathrm{A}$ converter. Three highly precise miniature bearings were used for the guide of the punch. A microscope was used for positioning of the punch and observation of the punching operation.

The movement of the punch agreed with that of the piezoelectric actuator. The coefficient of conversion from piezoelectric driver voltage to punch stroke was $0.45 \mu \mathrm{m} / \mathrm{V}$ and the punch movement signals were $10 \mathrm{~V}$ (punch stroke of $4.5 \mu \mathrm{m}$ ) for a rough feed, and $1 \mathrm{~V}(0.45 \mu \mathrm{m})$ for a fine feed. Punch speed was controlled by a change of the piezoelectric drive voltage, and varied from $6.4 \mu \mathrm{m} / \mathrm{sec}$ to $3.8 \mathrm{~mm} / \mathrm{sec}$. The punching process was carried out at a punch speed of $6.4 \mu \mathrm{m} / \mathrm{sec}$ without lubricant. The material feed was set and controlled by stepping motors for both the $\mathrm{X}$ and $\mathrm{Y}$ axis (movement of $0.1 \mathrm{~mm}$ ). The material to be punched was secured by way of clamps attached to the $\mathrm{X}$ axis.

For this research a direct current voltage of $140 \mathrm{~V}$ was used, which gave a vertical displacement of approximately $60 \mu \mathrm{m}$ of the punch. This was sufficient as the materials punched were $20 \mu \mathrm{m}$ to $50 \mu \mathrm{m}$ thick and the thickness of the section of the die with the hole was between $20 \mu \mathrm{m}$ to $30 \mu \mathrm{m}$ thick. If a larger displacement is required this can be achieved by simply increasing the voltage on the piezo controller as illustrated in Fig. 8. 


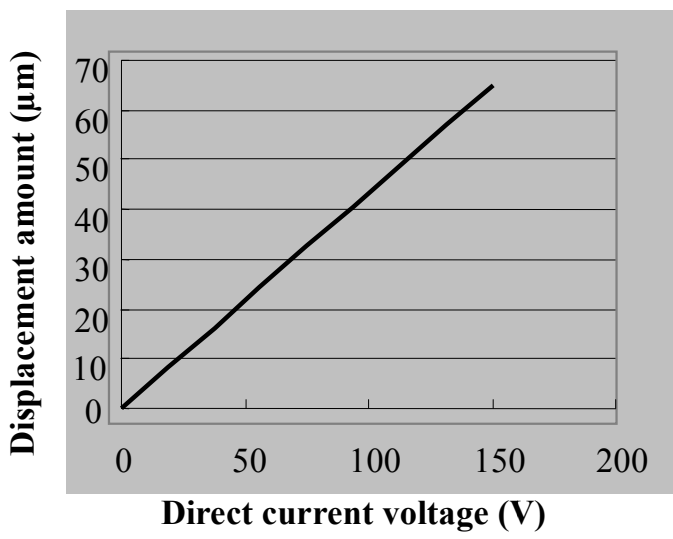

Fig.8 Displacement vs. direct current voltage

\section{Results and Discussion}

\subsection{Test Punching}

Punching was done using punches made from tool steel (SK3) and tungsten (W). Figure 9 shows the schematic drawing of the punching unit used for the punching operation. The average dimensions of the tool steel and tungsten punches used in this experiment are shown in fig.10. Punching was conducted on $20 \mu \mathrm{m}$ and $30 \mu \mathrm{m}$ thick copper, $25 \mu \mathrm{m}$ and 50 $\mu \mathrm{m}$ thick aluminum, and $20 \mu \mathrm{m}$ thick stainless steel foils. Table 4 shows the mechanical properties of the materials used. For the tool-steel, punching of the copper and aluminum foils was successful but unsuccessful for the stainless steel. Repeated attempts to punch the stainless steel foil resulted in bending of the punch tool. Figure 11 shows the punched holes of the copper and aluminum foils. From the micrographs the holes produced appeared free of burrs, cracks and other forms of deformation that would characterize poor hole production. The failure to punch the stainless steel foil implied that the result would be the same for other materials of similar and greater hardness. For the tungsten punch, trial punching was conducted on the same three materials, as well as on $20 \mu \mathrm{m}$ thick copper and $25 \mu \mathrm{m}$ thick aluminum foils. Except for the $25 \mu \mathrm{m}$ aluminum foil, and the $20 \mu \mathrm{m}$ copper foil the punching operation was successful. The holes produced were free of deformation, cracks and long burrs. Figure 12 shows the holes produce with the tungsten punch.

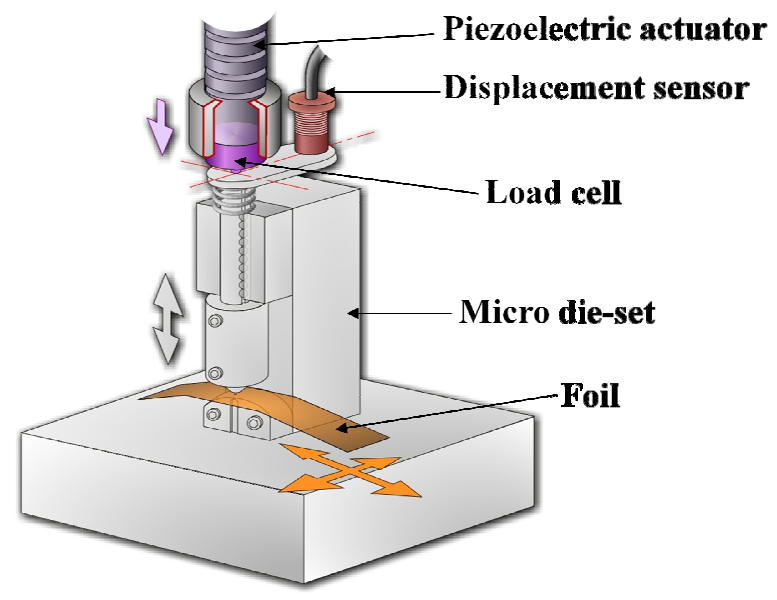

Fig.9 Schematic Drawing of punching unit 
However, the $25 \mu \mathrm{m}$ aluminum posed some difficulties during set up for punching. It was difficult to keep it from bending or deforming. After the punching operation some of the holes were not clean. Burrs and other forms of deformation were visible on some of the holes. This was assumed to be as a result of incorrect clearance between the punch and die.

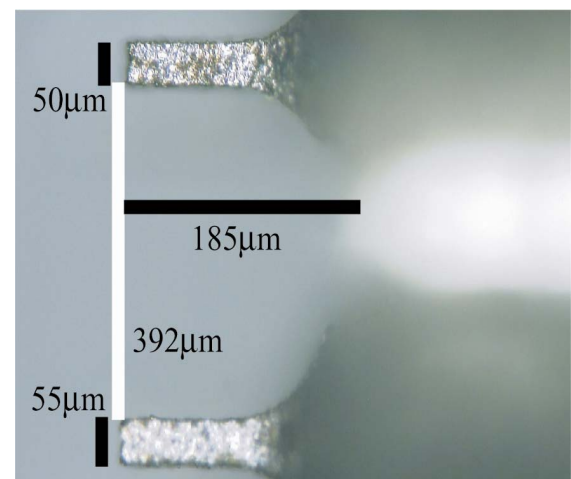

Tool-steel (SK3)

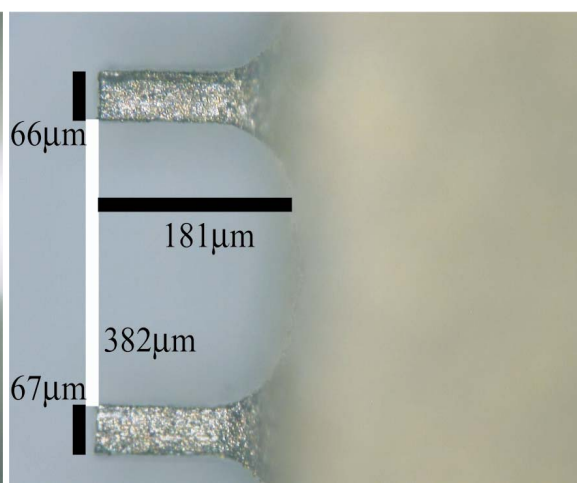

Tungsten (W)

Fig.10 Dimension of punches

Table 4. Mechanical properties of test materials

\begin{tabular}{|l|c|c|c|}
\hline Material & $\begin{array}{c}\text { Brinell } \\
\text { hardness }\end{array}$ & $\begin{array}{c}\text { Young's } \\
\text { modulus }\end{array}$ & $\begin{array}{c}\text { Ultimate } \\
\text { strength }\end{array}$ \\
\hline Aluminum & $15 \mathrm{HB}$ & $70 \mathrm{GPa}$ & $40 \sim 50 \mathrm{MPa}$ \\
\hline Copper & $35 \mathrm{HB}$ & $130 \mathrm{GPa}$ & $210 \mathrm{MPa}$ \\
\hline $\begin{array}{l}\text { Stainless } \\
\text { steel }\end{array}$ & $1250 \mathrm{HB}$ & $210 \mathrm{GPa}$ & $860 \mathrm{MPa}$ \\
\hline
\end{tabular}

Another reason was the thinness of the $25 \mu \mathrm{m}$ aluminum foil. This caused movement of the foil during the punching operation. In addition, the holes of the $20 \mu \mathrm{m}$ copper foil were not as clean as that of the $30 \mu \mathrm{m}$ copper foil. Small portions of the waste chips were not totally removed and burrs could be seen on one or two of the holes. This is not a major concern as this problem was solved by attaching a small vacuum pump to the die side of the hole which aided chip removal, as well as, helped kept the material flat on the die face and reduced movement during the punching operation.

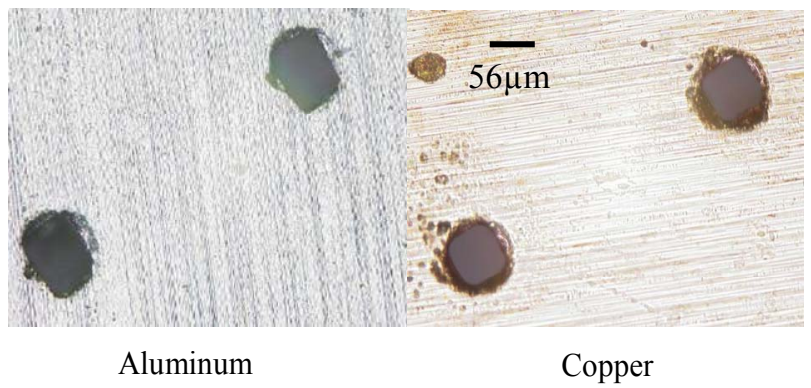

Fig.11 Micrographs of holes punched by tool-steel punch 


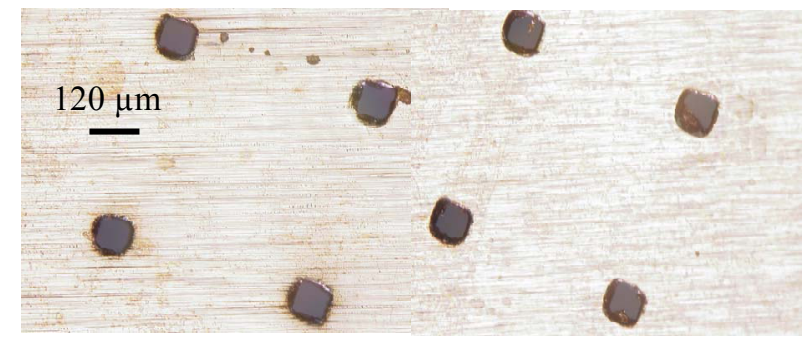

(a) $30 \mu \mathrm{m}$ thick copper

(b) $20 \mu \mathrm{m}$ thick copper

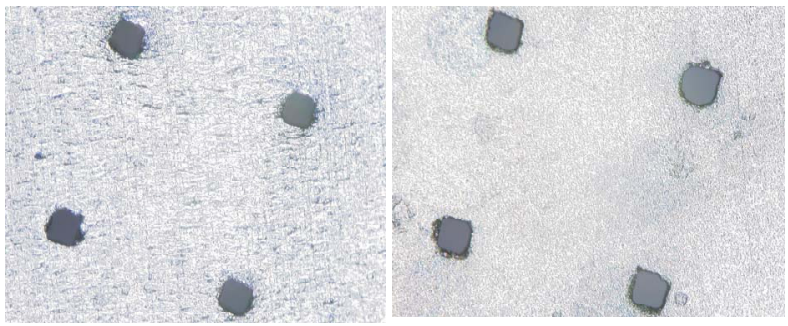

(c) $50 \mu \mathrm{m}$ thick aluminum

(d) $20 \mu \mathrm{m}$ thick stainless steel

Fig.12 Micrographs of holes by tungsten punch

From the experiments it was concluded that different materials can be used as the punch tool, as long as they are conductive. However, there will be limitations as to the type of materials that can be punched. In the case of the tool steel punch tool, the punching of the stainless steel foil was impossible. Even after repeated attempts and varying of the percentage clearance between the punch and die holes, the result was still the same. This failure was attributed to the hardness of the material. It was therefore concluded that tool steel can not be used to punch materials of similar hardness as that of stainless steel. On the other hand, the tungsten punch was able to punch all the tested materials. Based on these results, tungsten was confirmed as the best material for making the multi-point micro-punch. Although tungsten is usually a very difficult material to machine, using the processes of wire EDM negates such difficulties and makes the production of various shapes, length and sizes possible.

It was also confirmed that clearance between punch and die must be near optimum to obtain high quality holes. These are holes whose shear surfaces are free from cracks, burrs and any form of deformation. It was discovered that the percentage clearance was different for the different materials. The stainless steel requires a lager clearance than both copper and aluminum, with aluminum requiring the least.

\subsection{Effects of Clearance}

During trial punching it was observed that if the clearance was too small, secondary shearing occurred, which generally occurs when cutting softer metals with insufficient clearance between punch and $\mathrm{die}^{(10)}$. In cases where the clearance was too large excessive deformation was observed, mostly on the die side of the micro-holes. It also resulted in bending and breaking of the punch tool, which significantly reduced the life of the punching tool. Figure 13 shows the holes produced on the $25 \mu \mathrm{m}$ aluminum foil. This is one example of the defects that can occur when the clearance is incorrect. 


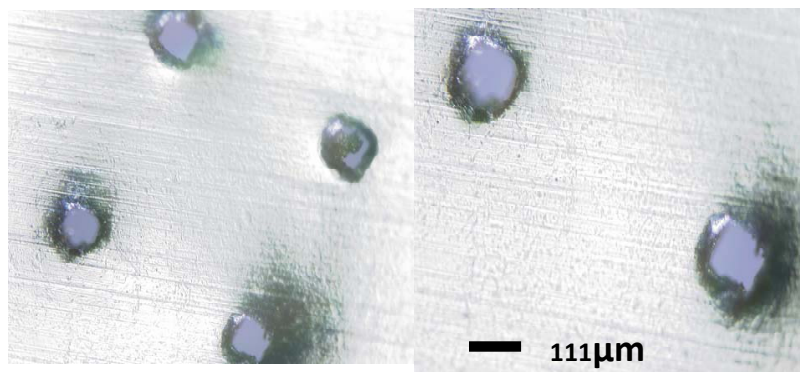

$25 \mu \mathrm{m}$ thick copper

Fig.13 Defects of holes on the $25 \mu \mathrm{m}$ thick aluminum foil

The desired clearance was achieved by varying the EDM processing parameters during the machining of the die holes, depending on the material thickness and the kind of material. For the copper and aluminum foils a capacitance of $1000 \mathrm{pF}$ was used and a capacitance of $2000 \mathrm{pF}$ for the stainless steel foil. This provided the clearances necessary to punched high quality holes in the various materials. Based on the results of the trial punching, it was concluded that a clearance of $13 \%$ to $18 \%$ was best for the $20 \mu \mathrm{m}$ stainless steel foil, $8 \%$ to $11 \%$ for the $30 \mu \mathrm{m}$ copper foil and $7 \%$ to $9 \%$ for the $50 \mu \mathrm{m}$ aluminum foil. Even with the appropriate clearance, bur formation still occurred, especially when punching the thinner and softer materials. A small vacuum pump was therefore added to the punching unit. This aided chip removal, helped secured the material to be punched to the die surface and reduced bur formation.

\section{Conclusion}

Based on the results of the trial punching, the following conclusions have been made:

1. Tungsten is the best material for making the punch.

2. Achieving near optimum clearance between punch and die is essential to successful punching.

3. During the die polishing process care must be taken to ensure that the die face is even. This is because unevenness will lengthen the discharge processing time and cause rounding of the punch-points.

4. For simultaneous machining of the die holes to be possible the punch-points must be of equal length and as much as is possible of equal size. This is a challenge that must be over come during the punch making process by controlling the discharge parameters and by correctly calculating the off-sets of the EDM wire.

5. The holes produce are clean and free from all forms of deformation and the punch surface showed no signs of crack or deformation even after repeated punching.

We therefore conclude that the multi-point micro punch system is capable of mass producing micro holes in various materials and as such can be applied to various manufacturing industries.

\section{References}

(1) Endo, T., Tsujimoto, T., Mitsui, K., Study of vibration-assisted micro-EDM-The effect of vibration on machining time and stability of discharge, Precision Engineering, Vol. 32, No. 4(2008) pp. 269-277.

(2) Mori, T., Development of ultra-fine piercing by $\mathrm{SiC}$ fiber punch, Transaction of ASME Journal of Manufacturing Science and Engineering, Vol.126 (2004), 
pp.659-665.

(3) Fujino, M., Yamamoto, M., Masuzawa, T., Micro-punching system as an application of WEDG, Institute of Industrial science, University Tokyo, Seisan-Kenkyu Vol. 39 (1987), pp. 277-280 “(in Japanese).”

(4) Chern, G., Wang, S., Punching of noncircular micro-holes and development of micro-forming," Precision Engineering, Vol. 3 (2007), pp. 210-217.

(5) Schonberger, R. J., World Class Manufacturing: The Next Decade, (1996) pp. 115-121, The Free Press, New York.

(6) Martellucci, S., Chester, A. N., Scheggi, A. M., Laser Applications for Mechanical Industry, NATO ASI Series (1993), pp. 280-293, Kluwer Academic, Boston and London.

(7) Vollertsen, F., Hu, Z., Niehoff, H.S., Theiler, C., State of the art in micro forming and investigations into micro deep drawing, Journal of Material Processing Technology (2004), pp. 151, 70-79.

(8) Hanada, K., Zhang, L., Sano, T., Fabrication of diamond dies for micro forming, Diamond Related Material (2003),Vol. 12, pp. 757-761 (Summary), View Record in Scopus (Cited By in Scopus (3).

(9) Jameson, E. C., Electrical Discharge Machining, (2001), pp. 103-253, Society of Manufacturing Engineers, Michigan.

(10) Eary, D. F., Reed, E. A., Techniques of Pressworking Sheet Metal (1958), pp. 10-33 Prentice-Hall, INC., Englewood Cliffs, New Jersey, 